\title{
More than a Box to Check: Research Sponsor and Clinical Investigator Perspectives on Making GCP Training Relevant
}

Teresa Swezey ${ }^{1,2}$, F. Hunter McGuire ${ }^{1,3}$ Patricia Hurley ${ }^{4}$, Janette Panhuis ${ }^{5}$, Kathy Goldstein ${ }^{6}$ Tina Chuck ${ }^{7}$, Carrie Dombeck $^{1,2}$, Brian Perry ${ }^{1,2}$, Christina Brennan ${ }^{7}$, Natasha Phrsai ${ }^{7}$, Amy Corneli ${ }^{1,2,3}$

${ }^{1}$ Clinical Trials Transformation Initiative, Duke University, Durham, NC, USA

${ }^{2}$ Department of Population Health Sciences, Duke University, Durham, NC, USA

${ }^{3}$ Duke Clinical Research Institute, Durham, NC, USA

${ }^{4}$ American Society of Clinical Oncology, Alexandria, VA, USA

${ }^{5}$ Population Health Research Institute, Hamilton, ON, Canada

${ }^{6}$ Regeneron Pharmaceuticals, Tarrytown, NY, USA

${ }^{7}$ The Feinstein Institutes for Medical Research, Northwell Health, Great Neck, NY, USA

Corresponding author: Teresa Swezey, teresa.swezey@duke.edu 


\section{ABSTRACT}

Background: Good clinical practice (GCP) training is the industry standard for ensuring the quality conduct of registrational clinical trials. However, concerns have been raised about whether the current structure and delivery of GCP training sufficiently prepares clinical investigators and their delegates to conduct clinical trials.

Methods: We conducted qualitative semi-structured interviews with 13 clinical investigators and 10 research sponsors to 1) examine characteristics of the quality conduct of sponsored clinical trials, including critical tasks and concerns perceived as essential for trial quality, 2) identify key knowledge and skills required to perform critical tasks, and 3) identify gaps and redundancies in GCP training and areas of improvement to ensure the quality conduct of clinical trials. We used applied thematic analysis to analyze the data.

Results: The top three tasks identified as critical for the quality conduct of clinical trials were obtaining informed consent, ensuring protocol compliance, and protecting participants' health and safety. Respondents acknowledged that GCP principles address each of these critical tasks; however, they described many challenges and burdens of GCP training, including high training frequency and repetitive content. Respondents suggested moving beyond GCP training as a mere check-box activity by making it more effective, engaging, and interactive. They also emphasized that applying GCP principles in a real-world, skills-based environment would increase the relevance of GCP training to investigators and their delegates.

Conclusion: Our findings indicate that although investigators and sponsors recognize that GCP training addresses critical tasks necessary to the quality conduct of clinical trials, they articulated the need for significant improvement in the design, content, and presentation of GCP training.

Keywords: Good clinical practice; clinical trials; quality; investigator training; clinical investigator 


\section{INTRODUCTION}

Regulations put forth by the U.S. Food and Drug Administration (FDA) [21 CFR 312.50, 21 CFR 312.53(a), 21 CFR 812.40 and 21 CFR $812.43(a)$ ] require that sponsors of registrational clinical trials select qualified investigators to conduct these trials. Good clinical practice (GCP) describes the scientific and ethical considerations involved in the quality conduct of clinical trials, as well as specifying investigator qualifications, roles, and responsibilities. Although not required by FDA regulations, clinical trial sponsors typically mandate training on GCP principles for investigators and their delegates prior to participation in each clinical trial and often consider such training as one of the metrics for demonstrating that investigators are qualified to conduct clinical trials.

Concerns have been raised over the current structure and delivery of GCP training to prepare clinical investigators and their delegates to conduct registrational clinical trials $[1,2]$. GCP training has been described as timeconsuming [3], emphasizing trial activities unrelated to research validity [4] and providing only the minimum of what is needed in the quality conduct of clinical trials [1]; redundant [1]; lacking specificity about the definition of site quality or clinical investigators' perspectives on site [5]; and having monitoring standards that vary widely across research studies and sites [6,7]. Despite being the industry standard, there is little evidence that completion of GCP training alone sufficiently qualifies investigators and their delegates in the quality conduct of clinical trials [1].

The Clinical Trials Transformation Initiative (CTTI) - a public-private partnership to develop and drive adoption of practices that will increase the quality and efficiency of clinical trials-conducted a two-phased project to gain a broader, evidence-based perspective on the efficient and effective qualification of site investigators and their delegates for the quality conduct of clinical trials. The first phase consisted of a literature review [8], expert interviews, and a survey to assess current GCP training, culminating in recommendations for streamlining GCP training practices $[1,9]$. These recommendations focused on four components of training: minimum essential elements, training frequency, training format, and evidence of completion $[1,9]$. 
As part of the second phase, CTTI conducted interviews to gather the views and experiences of clinical trial sponsors and clinical investigators to 1) examine characteristics of the quality conduct of sponsored clinical trials, including critical tasks and concerns perceived as essential for trial quality, 2) identify key knowledge and skills required to perform critical tasks, and 3) identify gaps and redundancies in GCP training and areas of improvement to ensure the quality conduct of clinical trials.

This paper reports on a subset of these objectives. First we present the top three most frequently mentioned critical tasks for ensuring the quality conduct of clinical trials, including respondents' identification of the GCP principles that adequately address those tasks. This is followed by respondents' suggested changes to GCP training on the top three critical tasks. Next, we provide an overview of respondents' views on the burden and redundancies of GCP training. Finally, we present respondents' suggestions for reconfiguring GCP training to better meet the needs of clinical trial investigators and sponsors.

\section{METHODS}

\section{Study Design and Participants}

We conducted a qualitative descriptive study $[10,11]$ using semi-structured interviews (SSIs) with clinical trial investigators and clinical trial sponsors.

\section{Participant Eligibility and Selection}

Clinical investigators were eligible to participate if they 1) are currently involved in a phase 3 clinical trial of drugs, biologics, and/or medical devices for registrational purposes; and 2) have participated in at least three phase 3 registrational trials within the past 5 years, for which GCP training was required for each trial. Research sponsors were eligible to participate if they required GCP training for investigators and their delegates for their trials. 
The CTTI Team for this project-which consisted of FDA representatives, industry representatives (pharmaceutical, biotech, device, and clinical research organizations), and members of patient advocacy groups, professional societies, investigator groups, and academic institutions-identified investigators and sponsors from among their professional networks whom they believed would be eligible. We purposefully selected [12] investigators to provide representation from a variety of research sites-academic, community-based health centers, and dedicated research sites - as well as those affiliated with research networks. Sponsors were purposefully selected on the basis of company size to ensure representation across small and large companies.

\section{Data Collection}

We contracted with RTI International, an independent nonprofit research institute, to conduct telephone interviews with clinical investigators and research sponsors between May 12 and August 4, 2017. Respondents were asked to share their thoughts on all of the critical tasks that must be conducted at sites to ensure the quality conduct of clinical trials; the three tasks they perceived as the most critical; the GCP principles that adequately address these top three critical tasks (participants were provided with the list in Figure 1); the topics they believe are missing from GCP training for each of the top three critical tasks; and redundancies in clinical trial training, including GCP training. Participants also responded to questions about the types of changes they felt need to be made to GCP training to ensure the quality conduct of clinical trials. All interviews were digitally audio recorded with the participant's permission. We also collected demographic information from each respondent.

\section{Ethics:}

1. Ethical conduct of trials: Clinical trials should be conducted in accordance with the ethical principles that have their origin in the Declaration of Helsinki, and that are consistent with GCP and the applicable regulatory requirement(s).

2. Benefits justify risks: Before a trial is initiated, foreseeable risks and inconveniences should be weighed against the anticipated benefit for the individual trial subject and society. A trial should be initiated and continued only if the anticipated benefits justify the risks.

3. Rights, safety, and well-being of subjects prevail: The rights, safety, and well-being of the trial subjects are the most important considerations and should prevail over interests of science and society.

\section{Protocol and science:}

4. Nonclinical and clinical information supports the trial: The available nonclinical and clinical information on an investigational product should be adequate to support the proposed clinical trial. 
5. Compliance with a scientifically sound, detailed protocol: Clinical trials should be scientifically sound, and described in a clear, detailed protocol.

\section{Responsibilities:}

6. IRB/IEC approval prior to initiation: A trial should be conducted in compliance with the protocol that has received prior institutional review board (IRB)/independent ethics committee (IEC) approval/favorable opinion.

7. Medical care/decisions by qualified physician: The medical care given to, and medical decisions made on behalf of, subjects should always be the responsibility of a qualified physician.

8. Each individual is qualified to perform his/her tasks: Each individual involved in conducting a trial should be qualified by education, training, and experience to perform his or her respective task.

\section{Informed Consent:}

9. Freely given from every subject prior to participation: Freely given informed consent should be obtained from every subject prior to clinical trial participation.

\section{Data quality and integrity:}

10. Accurate reporting, interpretation, and verification: All clinical trial information should be recorded, handled, and stored in a way that allows its accurate reporting, interpretation, and verification.

11. Protects confidentiality of records: The confidentiality of records that could identify subjects should be protected, respecting the privacy and confidentiality rules in accordance with the applicable regulatory requirement(s).

\section{Investigational Products:}

12. Conform to GMPs and used per protocol: Investigational products should be manufactured, handled, and stored in accordance with applicable good manufacturing practice (GMP). They should be used in accordance with the approved protocol.

\section{Quality Control/Quality Assurance:}

13. Systems with procedures to ensure quality of every aspect of the trial: Systems with procedures that assure the quality of every aspect of the trial should be implemented.

\section{Figure 1. 13 Principles of ICH-GCP [13, 14]}

\section{Data Analysis}

We used descriptive statistics to summarize the demographic data. All interviews were transcribed verbatim following a transcription protocol [15]. Applied thematic analysis [16] was used to analyze respondents' narratives, using a two-stage deductive and inductive analysis approach. First, three analysts applied structural codes (based on the specific interview topics and organized according to the research objectives) using NVivo 11, a qualitative data analysis software program (QSR International Pty Ltd 2015). Inter-coder agreement was assessed on four interviews ( $17 \%$ of the transcripts, two investigator and two research sponsors). Discrepancies in code application were resolved through group discussion, and edits were subsequently made to the codebook. 
Analysts then inductively identified content-driven codes in each structural coding report and applied these content codes to the data using NVivo 11 . The content-driven coding reports were reviewed to identify themes and sub-themes related to the objectives based on their frequency. Data summary reports were produced describing these themes and sub-themes, together with illustrative quotes.

\section{Ethics}

The Duke University Health System Institutional Review Board (IRB) and an IRB within the Office of Research Protection at RTI reviewed the study protocol and determined that the research is exempt from IRB review.

\section{RESULTS}

\section{Study Population}

We interviewed 13 clinical investigators and 10 research sponsors. Clinical investigators represented various specialties and organizations, and had 10 to 35 years of experience in their field of medicine, which ranged from highly specialized clinical practice (e.g., oncology and hematology) to more general practice (e.g., general internal medicine and family medicine). Investigators were affiliated with a variety of types of research sites and most (62\%) stated that their site belonged to a research network. The number of years leading phase 3 clinical trials of drugs, biologics, and/or medical devices for registrational purposes as the principal investigator (PI), co-PI, and sub-PI varied greatly among investigators (range 1 to 31 years), as did the number of trials the investigators had led (3 to 300) (Table 1).

\section{Organization of Current Affiliation}

Academic institution or academic health system with research and education opportunities

Community-based out-patient clinic or private practice with primary clinical responsibilities

Community-based hospital with no affiliated academic institution

Dedicated research site with no affiliated clinical practice responsibility Other*

$1(7.7)$

\section{Specialty}

Cardiology

General Internal Medicine

$3(23.1)$

Pulmonary and Critical Care

$2(15.4)$ 


\begin{tabular}{|c|c|}
\hline Primary Care & $1(7.7)$ \\
\hline Pediatrics & $1(7.7)$ \\
\hline Psychiatry & $1(7.7)$ \\
\hline Family Medicine & $1(7.7)$ \\
\hline Oncology and Hematology & $1(7.7)$ \\
\hline \multicolumn{2}{|l|}{ Years in Specialty } \\
\hline Mean & 24.5 \\
\hline Median (range) & $30.0(10-31)$ \\
\hline $10-19$ years & $3(23.1)$ \\
\hline 20-29 years & $3(23.1)$ \\
\hline $30-35$ years & $7(53.8)$ \\
\hline \multicolumn{2}{|c|}{ Years as $\mathrm{PI} / \mathrm{co}-\mathrm{PI} /$ sub-I of Registrational Trials } \\
\hline Mean & 14.8 \\
\hline Median (range) & 30.0 (range 1-31) \\
\hline $1-10$ years & $4(30.8)$ \\
\hline $11-20$ years & $5(38.5)$ \\
\hline $21-30$ years & $3(23.1)$ \\
\hline$>30$ years & $1(7.7)$ \\
\hline \multicolumn{2}{|l|}{ Number of Registrational Trials Conducted } \\
\hline 3-20 trials & $3(23.1)$ \\
\hline $21-40$ trials & $2(15.4)$ \\
\hline $41-60$ trials & $2(15.4)$ \\
\hline $81-100$ trials & $3(23.1)$ \\
\hline$>100$ trials & $3(23.1)$ \\
\hline \multicolumn{2}{|c|}{ Type(s) of Products Investigated in Registrational Trials } \\
\hline Drugs, either therapeutic or preventive & $13(100)$ \\
\hline Biologics & $8(61.5)$ \\
\hline Vaccines & $7(53.8)$ \\
\hline Devices & $7(53.8)$ \\
\hline Combination Products & $6(46.2)$ \\
\hline Other** & $2(15.4)$ \\
\hline \multicolumn{2}{|c|}{ Investigator's Site Belongs to a Research Network } \\
\hline Yes & $8(61.5 \%)$ \\
\hline No & $5(38.5 \%)$ \\
\hline
\end{tabular}

Table 1. Investigator Demographics

Research sponsors represented pharmaceutical or medical device companies of various sizes and types of

products. Sponsor representatives' roles varied and included vice presidents, senior or executive-level directors, departmental directors or heads, and managers; years of experience in these roles ranged from 1 to 23 years. All sponsor representatives had partnered with academic institutions to conduct some of their registrational trials; most had partnered with community-based outpatient clinics and hospitals ( $n=9$ and $n=7$, respectively), and half had partnered with dedicated research sites (Table 2). 
Sponsor Demographics $(\mathrm{n}=10)$

n (\%)

Type(s) of Products Company Develops

Drugs, either therapeutic or preventive

$5(50)$

Vaccines

$1(10)$

Devices

$4(40)$

Biologics

$4(40)$

Combination products

$6(60)$

Size of Company

A micro-size company (market cap under $\$ 300$ million)

A small-size company (market cap at $\$ 300$ million to under $\$ 2$ billion)

A mid-size company (market cap between $\$ 2$ billion and $\$ 10$ billion)

$4(40)$

A large-size company (market cap over $\$ 10$ billion)

$3(30)$

Prefer not to respond

$1(10)$

Years Sponsor Engaged in Registrational Phase III Clinical Trials

Mean

Median

3-5 years

$1(10)$

6-10 years

$0(0)$

$11-15$ years

$3(30)$

$16-20$ years

$3(30)$

21-25 years

$3(30)$

Therapeutic Areas of Registrational Phase III Clinical Trials

Cardiology

Immunology

$2(20)$

Gastroenterology

$1(10)$

Hematology

$1(10)$

Infectious disease

$1(10)$

Neurology

$1(10)$

Oncology

$1(10)$

Ophthalmology

$1(10)$

Rheumatology

$1(10)$

Other**

* Conducts genetic research

** Pain, Neuromodulation, Surgical Products, Critical Care, Peripheral Artery Disease, Inflammation, Rare Disease,

Anesthesiology, Endurology, Targeted Temp. Management, Home Care, Structural Heart

Table 2. Sponsor Demographics

\section{Top Three Critical Tasks and Associated GCP Principles}

Figure 2 displays all critical tasks described by respondents. Table 3 displays the top three critical tasks, their associated GCP principles as linked by participants, and representative quotes. The most frequently mentioned top three critical tasks were 1) obtaining informed consent, 2) ensuring protocol compliance, and 3) protecting participants' health and safety. Most respondents cited more than one GCP principle as adequately addressing each of the top three critical tasks, and there was overlap between the principles cited for each task. 
- Obtain informed consent

- Ensure qualified staff perform assigned roles and responsibilities

- Ensure data quality, documentation, and accuracy

- Comply with protocol

- Assign qualified physicians for study oversight and medical care of participants

- Implement quality assurance/quality control procedures

- Ensure participant safety

- Use investigational product per protocol

- Ensure ethical conduct of the trial

- Obtain IRB approval prior to initiation and amendments

- Report adverse events, deviations, and respond to queries

- Provide training on both protocol and GCP

- Obtain adequate resources to conduct study

- Encourage communication among all levels of the team

- Ensure active involvement of assigned staff in conducting study procedures

- Ensure buy-in from the medical doctors conducting trial to ensure quality control

- Create a clinical trial environment that emphasizes ethical conduct

- Ensure no misaligned incentives

- Incorporate PI, medical staff in protocol, study, case report form development (input, feedback)

- View mentorship as critical task

Figure 2. All Critical Tasks Mentioned by Respondents as Necessary for the Quality Conduct of Clinical Trials

\begin{tabular}{|c|c|c|}
\hline Top Three Critical Tasks & $\begin{array}{l}\text { Related GCP Principles Cited by } \\
\text { Respondents }\end{array}$ & Respondent Quotes \\
\hline Informed Consent & $\begin{array}{l}\text { GCP Domain: Ethics } \\
\text { Ethical conduct of trials; Benefits justify } \\
\text { risks; Rights, safety, and well-being of } \\
\text { subjects prevail } \\
\text { GCP Domain: Informed Consent } \\
\text { Freely given from every subject prior to } \\
\text { participation } \\
\text { GCP Domain: Responsibilities } \\
\text { Each individual is qualified to perform } \\
\text { his/her tasks }\end{array}$ & $\begin{array}{l}\text { I have to have informed consent [as a top } \\
\text { three critical task], because that's what starts } \\
\text { the process. (Investigator) } \\
\text { I'd say informed consent is very important, } \\
\text { that the patient is educated on risks and } \\
\text { benefits. I think one of the biggest abuses } \\
\text { could be the desperate patient that is looking } \\
\text { for a cure and has false expectations from } \\
\text { the study, so patients need to be made aware } \\
\text { that this is an investigational drug, and } \\
\text { there's no guarantee that it's going to help } \\
\text { them, and there are risks involved in } \\
\text { participating in a study. (Sponsor) }\end{array}$ \\
\hline Protocol Compliance & $\begin{array}{l}\text { GCP Domain: Responsibilities } \\
\text { Each individual is qualified to perform } \\
\text { his/her tasks; Medical care/decisions by } \\
\text { qualified physician } \\
\text { GCP Domain: Protocol and Science }\end{array}$ & $\begin{array}{l}\text { Because at the end of the day you can't use } \\
\text { the data if you have too many protocol } \\
\text { violations. (Sponsor) } \\
\text { And if you have inexperienced support staff } \\
\text { or physicians that aren't trained in the }\end{array}$ \\
\hline
\end{tabular}




\begin{tabular}{|c|c|c|}
\hline Top Three Critical Tasks & $\begin{array}{c}\text { Related GCP Principles Cited by } \\
\text { Respondents }\end{array}$ & Respondent Quotes \\
\hline & $\begin{array}{l}\text { Compliance with a scientifically sound, } \\
\text { detailed protocol } \\
\text { GCP Domain: Data Quality and Integrity } \\
\text { Accurate reporting, interpretation, and } \\
\text { verification; Protects confidentiality of } \\
\text { records }\end{array}$ & $\begin{array}{l}\text { specialty of the disease in hand, you're more } \\
\text { likely to get junk data and not follow the } \\
\text { protocol correctly. (Sponsor) }\end{array}$ \\
\hline $\begin{array}{l}\text { Protecting Participants' } \\
\text { Health and Safety }\end{array}$ & $\begin{array}{l}\text { GCP Domain: Responsibilities } \\
\text { Medical care/decisions by qualified } \\
\text { physician } \\
\text { GCP Domain: Ethics } \\
\text { Rights, safety, and well-being of subjects } \\
\text { prevail }\end{array}$ & $\begin{array}{l}\text { That's being an MD and taking the } \\
\text { Hippocratic Oath, you have sworn that you'll } \\
\text { first do no harm. Data are important and } \\
\text { studies are important, but individual lives are } \\
\text { more important. So, if we see there is } \\
\text { something unsafe, no matter how much the } \\
\text { sponsor might want the study, we have to } \\
\text { make sure the patient is taken care of first. } \\
\text { (Investigator) } \\
\text {... the rights, safety and well-being of the } \\
\text { subjects, because if the study is being } \\
\text { properly monitored by medical professionals, } \\
\text { and they are following up on the patient and } \\
\text { the data throughout the trial, then they } \\
\text { should have the best interest of the patient in } \\
\text { mind, and be monitoring for their safety } \\
\text { throughout the study. (Investigator) }\end{array}$ \\
\hline
\end{tabular}

Table 3. Top Three Critical Tasks and their Related GCP Principles

\section{Informed Consent}

Informed consent was the most frequently identified critical task listed in respondents' "top three." Respondents stressed that informed consent was the foundation for clinical research. They also emphasized the importance of informed consent as a process for ensuring that potential participants are fully informed and understand all the risks and benefits of study participation and what they are being asked to do, so they can make a truly informed decision. Respondents linked the critical task of "informed consent" to the GCP domains of ethics, informed consent, and responsibilities. 


\section{Protocol Compliance}

The second top critical task identified was protocol compliance. Respondents described protocol complianceespecially to inclusion/exclusion criteria, proper screening, and enrollment-as critically important because it impacts the integrity of the data and ultimately the study's findings about whether or not the investigational product was beneficial. Protocol compliance also ensures study participants' safety. Respondents linked the critical task of "protocol compliance" to the GCP domains of responsibilities, protocol and science, and data quality and integrity.

\section{Protecting Participants' Health and Safety}

The third top critical task described by respondents was participant safety. Respondents stressed the importance of protecting study participants above all else. The critical task of "protecting participants' health and safety" was linked to the GCP domains of responsibilities and ethics.

\section{Suggested Changes to GCP Training on the Top Three Critical Tasks}

Table 4 lists suggested changes to GCP training for the top three critical tasks, based on respondents' views on content that is missing from GCP training. Suggested changes generally focused on adding to existing definitions, guidance, and training.

\begin{tabular}{|c|c|}
\hline Top Three Critical Tasks & Type of Modification Needed \\
\hline Informed Consent & $\begin{array}{l}\text { - More training on how to account for vulnerable subjects and how to use LARs and } \\
\text { impartial witnesses } \\
\text { - Better definition of and guidance on the informed consent process } \\
\text { - Training on how to write clearer, more concise and understandable consent forms } \\
\text { - Training for study staff on the need to adequately inform patients about responsibilities } \\
\text { - } \text { they are committing to if they join the trial (e.g., keeping a trial diary) } \\
\text { study guidance on investigators' responsibilities to report results of related research to } \\
\text { study parts }\end{array}$ \\
\hline Protocol Compliance & $\begin{array}{l}\text { - Define what constitutes a clinically significant vs. a non-significant lab abnormality } \\
\text { - Define what constitutes a protocol deviation or violation } \\
\text { - Guidance on addressing the issue that non-study physicians involved in patient care may } \\
\text { - } \text { cause participants' non-compliance with the protocol } \\
\text { - More guidance and training on how to write appropriate inclusion/exclusion criteria }\end{array}$ \\
\hline
\end{tabular}




\begin{tabular}{|c|c|}
\hline Top Three Critical Tasks & Type of Modification Needed \\
\hline & $\begin{array}{l}\text { - Guidance and training should emphasize timeliness in data entry and the importance of } \\
\text { making current data available to sponsors } \\
\text { Training needs to be tailored to the audience to account for various skill levels and } \\
\text { experience of study staff in order to ensure understanding of and adherence to protocol } \\
\text { specifics }\end{array}$ \\
\hline $\begin{array}{l}\text { Protecting Participants' } \\
\text { Health and Safety }\end{array}$ & $\begin{array}{l}\text { - Clearly define specific endpoints and adverse events for particular protocols and better } \\
\text { define the monitoring period, providing specific time frames for subject re-contact, } \\
\text { particularly in lengthy studies } \\
\text { - Guidance needed about importance of informing participants' other physicians about their } \\
\text { trial participation, given the possibility of adverse events occurring outside of the organ or } \\
\text { disease under study } \\
\text { - Guidance needed on importance of maintaining sufficient staffing to provide adequate } \\
\text { oversight, training, and conduct of research activities } \\
\text { - Guidance and training should emphasize importance of ensuring that the study team has } \\
\text { expertise in the field of study, as having a good clinical background in the disease area } \\
\text { being treated is important to ensuring patient safety } \\
\text { - Training should emphasize how patient data may be used in the future, e.g., genetic data, } \\
\text { as this may impact patient safety and rights for many years after study completion }\end{array}$ \\
\hline
\end{tabular}

Table 4. Suggested Changes to GCP Training for Top Three Critical Tasks

\section{Redundancies in GCP Training}

Investigators described several training components they felt were redundant and did not improve investigators' ability to conduct critical tasks. The general review of the rationale for GCP was one of the most commonly cited complaints, with investigators particularly seeming to dislike having to repeatedly review historical background (e.g., the Belmont Report, the Tuskegee Experiment). Sponsors displayed an awareness of investigator frustration with the frequent repetition of general review of GCP and in many instances reported that their trainers had a tendency to gloss over GCP basics as a result, one respondent noted:

I think we oftentimes go very quickly through the GCP slides, because we just assume that everybody's already heard them 100 times and nobody is paying attention ..., so trying to think maybe a little more creatively about how to train.

Moreover, the most common challenge respondents cited about GCP training in general, prior to any specific questions on training redundancies, centered on frequent GCP trainings and its repetitive content. The majority of investigators felt that requirements to re-certify GCP training within a certain time frame or to re-certify for every trial were onerous, particularly given that the content of such training is often the same. An investigator stated 
that the requirement to participate in repetitious and redundant GCP training was a deterrent to physician participation in clinical trials:

We have actually had physicians in our practice who don't participate in clinical trials because of the requirement to re-certify frequently in things that they already know that takes several hours of time on the weekend. Asking people to re-do these things every three years for 4-6 hours on a day off is a problem. It has impaired my ability to get half of the people in my practice to participate as sub-I's in clinical trials. They see it as a waste of time, and they see being asked to do the same things over and over again as insulting.

Other training topics investigators noted that tend to be repetitive included adverse events, data quality/integrity, forms/processes/labs, and informed consent. Sponsors noted that routine training on these topics tended to be "canned," take a lot of time, and not necessarily be tailored to the protocol. An investigator commented on the repetition of standard topics at almost every training session:

What is repeated [is] adverse events [and] obtaining informed consent at the investigators' meeting ... And you get it from every meeting ... I see several monitors several times, so they say, "Yep, we know you've been through this before." It turns out to be a waste of their time, and a waste of my time.

Some respondents, however, viewed redundancy as a positive feature of GCP training. They explained that repetition of GCP material helped to reinforce key concepts and could be beneficial for some investigators and study staff to hear again, which may ultimately be beneficial for protecting patients. An investigator said:

Some of the redundancy is just whether we have different studies. In this respect, I guess there's nothing wrong with that consistency. But, it seems like we kind of hear some of the same things around EDC, data entry, AEs and SAEs, they are pretty standard. I'm not saying that's wrong; I think that's good. It's just reinforcing that. I'm not looking at it as redundant, but more reinforcement for those areas. ... When I think of something as a critical process and it's repeated, it's reinforced, because it's that critical. That's how I differentiate. Redundancy has more of a "we really need to do this over and over again." Which tells me it has less value, which I think that's what you are alluding to. 
A sponsor said:

... sometimes there's good in being redundant, particularly when we talk about protecting patients. I think when there is redundancy, it is appropriate. I wouldn't say that there's something on here that doesn't prepare physicians for conducting clinical studies. At least I don't think so.

Additionally, some sponsors noted that investigator inattention to GCP content does not necessarily translate to proficiency with GCP basics, despite frequent repetition:

... this is kind of a gut thing for me, both when you see the body language on sites when we start talking about GCP, it's like "I already know." So, then we won't have any protocol deviations, we won't have any eligibility violations, there won't be any issues with reporting, right? Invariably there are... I think there's a fine balance on all of it. I see physicians looking at their watch when I tell them how to deploy a stent. "I just did 30 of these this week so I don't need any help on that." ... I would tend to think some of the things we talk about in GCP, people act like, "I've been doing this for 20 years, I don't need to be told again." That's probably the first thing that comes up, which is unfortunate, because that's what our whole conversation is about.

\section{Other Challenges with GCP Training}

Investigators described several other challenges they had experienced with GCP training. They noted that GCP training was time-consuming and had the potential to be perceived as just another box to check off and something to get through as quickly as possible, rather than as an important consideration for patient safety. An investigator explained:

It's often perceived as something just to get through. And you know what you're supposed to do, and you're kind of given this forced video feed to watch and answer a few questions to make sure you've gotten it, and if you don't get the questions right you just re-take the test.

Investigators further described GCP training as uninteresting, both as a result of the content covered and the format and style in which the training is delivered. Lack of centralized and standardized GCP training that is accepted by all sponsors is also perceived as a burden by some investigators because sponsors generally require 
investigators and their delegates to complete GCP training for each clinical trial.

\section{Feedback on Improvements to GCP Training in General and Suggested Solutions}

Respondents suggested changes to current GCP training to ensure the quality conduct of clinical trials, beyond the top three critical tasks. Investigators and sponsors focused on slightly different issues. Investigators touched on the frequency, standardization, methods, and content of GCP training, with some investigators commenting on only one of these areas, and others proposing changes to multiple aspects of training. Overall, investigator comments tended to focus both on strategies for alleviating training burden and for reviving interest in the training topics. Sponsors primarily focused on strategies for capturing trainees' interest and ensuring attention to the material. Investigators' and sponsors' feedback are presented separately in Table 5. 


\begin{tabular}{|c|c|c|c|c|}
\hline \multirow[t]{2}{*}{ Topic } & \multicolumn{2}{|r|}{ Investigators } & \multicolumn{2}{|r|}{ Sponsors } \\
\hline & Change Suggested & Representative Quotes & Change Suggested & Representative Quotes \\
\hline $\begin{array}{l}\text { Training } \\
\text { Frequency }\end{array}$ & $\begin{array}{l}\text { - Decrease frequency } \\
\text { of GCP training } \\
\text { - Less frequent or } \\
\text { more condensed } \\
\text { training for } \\
\text { individuals who are } \\
\text { more advanced in } \\
\text { their research careers } \\
\text { or who have } \\
\text { demonstrated } \\
\text { understanding of the } \\
\text { topic } \\
\text { - Establish centralized } \\
\text { single, mandatory } \\
\text { annual GCP training } \\
\text { to replace multiple } \\
\text { sponsor-specific } \\
\text { trainings }\end{array}$ & $\begin{array}{l}\text { So, you say how do we improve GCP } \\
\text { training? You know what, I want less GCP } \\
\text { training. It's gotten so burdensome. I'm } \\
\text { just one person, and if you have } 40 \text { staff } \\
\text { at a site, so you have all that redundancy } \\
\text { with } 40 \text { people, each one on } 5 \text { trials, } \\
\text { except for me, I'm on all of them. It's } \\
\text { stupid, really, how bad it is. So, I don't } \\
\text { think there's any more need. I think they } \\
\text { need to do less. } \\
\text { I would like to see a centralized GCP } \\
\text { training for whoever, whether it's } \\
\text { investigators or whoever is participating } \\
\text { in the clinical trial, I'd like to see } \\
\text { something more centralized so we're not } \\
\text { having to do all of these sponsor specific } \\
\text { trainings. So, if I do CITI training, or } \\
\text { whatever the recognized GCP training is, } \\
\text { if that's done on-, and quite frankly, I } \\
\text { don't think it would hurt to have it on an } \\
\text { annual basis, rather than every two } \\
\text { years. }\end{array}$ & NA & NA \\
\hline $\begin{array}{l}\text { Training } \\
\text { Standardization }\end{array}$ & $\begin{array}{l}\text { - Establish universally } \\
\text { recognized GCP } \\
\text { training that is } \\
\text { accepted by all } \\
\text { sponsors as valid } \\
\text { - Consider medical } \\
\text { specialty re- } \\
\text { certifications as a } \\
\text { model for changes to } \\
\text { GCP training }\end{array}$ & $\begin{array}{l}\text { Well, I think there's, from what I } \\
\text { understand, a national curriculum. ... } \\
\text { Almost like if a physician has a medical } \\
\text { specialty, and they have to be re-certified } \\
\text { every number of years. I would think that } \\
\text { GCP might be that way, as opposed to } \\
\text { allowing you to do it on the computer } \\
\text { whenever you want, and you go through } \\
\text { it and don't look at. You don't pay as } \\
\text { much attention. ... I think it provides a }\end{array}$ & $\begin{array}{l}\text { Reach industry-wide } \\
\text { agreement on a core set } \\
\text { of training standards and } \\
\text { materials, to ensure that } \\
\text { all investigators are } \\
\text { starting from the same } \\
\text { framework and to } \\
\text { reduce variance in } \\
\text { understanding of key } \\
\text { GCP principles that may }\end{array}$ & $\begin{array}{l}\text { I think that what would be ideal is if } \\
\text { people who are going to be doing clinical } \\
\text { trials like this would agree on like a } \\
\text { harmonization of one stop shopping. ... if } \\
\text { we all had something similar, then, you } \\
\text { know, you can show that you were } \\
\text { accredited or certified or trained, or } \\
\text { whatever language you want to put } \\
\text { around it, but it's one stop, one spot, we } \\
\text { can all be talking the same thing. }\end{array}$ \\
\hline
\end{tabular}




\begin{tabular}{|c|c|c|c|c|}
\hline \multirow[t]{2}{*}{ Topic } & \multicolumn{2}{|r|}{ Investigators } & \multicolumn{2}{|r|}{ Sponsors } \\
\hline & Change Suggested & Representative Quotes & Change Suggested & Representative Quotes \\
\hline & $\begin{array}{l}\text { Make training } \\
\text { consistent across } \\
\text { sponsors to include } \\
\text { agreed-upon critical } \\
\text { aspects that must be } \\
\text { addressed to ensure } \\
\text { that trainees are } \\
\text { equally qualified with } \\
\text { at least a basic level } \\
\text { of clinical trial } \\
\text { knowledge }\end{array}$ & $\begin{array}{l}\text { level of confidence for the public and for } \\
\text { subjects. And it should for society for } \\
\text { government, for whoever. But, it will also } \\
\text { provide the recognition that you remain } \\
\text { knowledgeable about the area. }\end{array}$ & $\begin{array}{l}\text { have been taught slightly } \\
\text { differently to different } \\
\text { sites } \\
\text { - Recognize the challenges } \\
\text { to implementing } \\
\text { universal training criteria } \\
\text { and standardized GCP } \\
\text { training in industry } \\
\text { sponsored clinical trials }\end{array}$ & $\begin{array}{l}\text { I think in reality, the practical way it still } \\
\text { works is every manufacturer and every } \\
\text { sponsor of a study does their own type of } \\
\text { GCP training, or they have their own } \\
\text { process... Everybody does something } \\
\text { different, and we've tried to come up } \\
\text { with recommendations on how to } \\
\text { standardize that, but it's not taken. ...at } \\
\text { least across the United States it's not } \\
\text { standardized, and it's not standardized } \\
\text { outside the United States either. But if we } \\
\text { could reach some kind of, "Hey, this is a } \\
\text { standard that we're all going to follow," I } \\
\text { think that would be helpful, so that } \\
\text { investigators who participate in a lot of } \\
\text { research by a lot of different sponsors } \\
\text { aren't undergoing the same GCP training } \\
\text { multiple times. ... know we've tried that } \\
\text { at CTTl and made recommendations, and } \\
\text { it's just not quite there yet. }\end{array}$ \\
\hline $\begin{array}{l}\text { Training } \\
\text { Conduct and } \\
\text { Methods }\end{array}$ & $\begin{array}{l}\text { - Move beyond GCP } \\
\text { training as just } \\
\text { another box to check } \\
\text { by making it more } \\
\text { engaging and } \\
\text { interactive } \\
\text { - Incorporate apps, } \\
\text { quizzes, or games into } \\
\text { GCP training } \\
\text { - Institute a system of } \\
\text { just-in-time } \\
\text { approaches }\end{array}$ & $\begin{array}{l}\text {... in this day and age with so many inputs } \\
\text { in our lives with the EMR, email, etcetera, } \\
\text { the expectation is we need that } \\
\text { information at the time you're using it. } \\
\text { And I think that's where a little bit of the } \\
\text { training, the missed opportunity, is } \\
\text { figuring out, how do you provide the right } \\
\text { information at the right time to the right } \\
\text { person. ... it's almost like how we } \\
\text { initiated procedures in the clinical } \\
\text { practice to reduce mistakes. ... just to } \\
\text { pause as part of the culture at the time }\end{array}$ & $\begin{array}{l}\text { - Move beyond GCP } \\
\text { training as just another } \\
\text { box to check by making } \\
\text { it more engaging and } \\
\text { interactive } \\
\text { - Incorporate apps, } \\
\text { quizzes into GCP training } \\
\text { - Invite key opinion } \\
\text { leaders to present at } \\
\text { sponsor meetings, both } \\
\text { for the information } \\
\text { about real-world }\end{array}$ & $\begin{array}{l}\text { The question is how well are they } \\
\text { presented and you get the point across, } \\
\text { or are they just a "check the box } \\
\text { discussion" that has to occur. I think GCP } \\
\text { is the hardest part of site training often, } \\
\text { because either the monitor or the trainer } \\
\text { glosses over it, or the physician has } \\
\text { convinced him or herself that they are } \\
\text { experts on it, and so they don't pay } \\
\text { attention to it. So, it's not so much } \\
\text { redundant as it's how to engage them in } \\
\text { the dialog to make sure that you're }\end{array}$ \\
\hline
\end{tabular}




\begin{tabular}{|c|c|c|c|c|}
\hline \multirow[t]{2}{*}{ Topic } & \multicolumn{2}{|r|}{ Investigators } & \multicolumn{2}{|r|}{ Sponsors } \\
\hline & Change Suggested & Representative Quotes & Change Suggested & Representative Quotes \\
\hline & $\begin{array}{l}\text { incorporating real-life } \\
\text { pauses and checks on } \\
\text { GCP } \\
\text { - Increase mentorship } \\
\text { for new investigators } \\
\text { to guide them through } \\
\text { the details of GCP in a } \\
\text { clinical setting and } \\
\text { ensure they have a full } \\
\text { understanding of what } \\
\text { is required for the } \\
\text { quality conduct of a } \\
\text { clinical trial }\end{array}$ & $\begin{array}{l}\text { you are doing that component of the } \\
\text { protocol. ... I think that's where if people } \\
\text { had the mindset, "I'm about to consent } \\
\text { this patient. There are things I need to } \\
\text { remember about the consent process. It's } \\
\text { making the appropriate explanation of } \\
\text { the study, what randomization is, what } \\
\text { your risks are, your cost, signing the } \\
\text { forms on each page so that there's } \\
\text { recognition that there's been a review, } \\
\text { and appropriate signatures on the back } \\
\text { page. OK, before I do this, I reminded } \\
\text { myself what's required, and now I'm } \\
\text { going to execute this procedure." }\end{array}$ & $\begin{array}{l}\text { situations they can } \\
\text { convey, and as a draw } \\
\text { for busy physicians, to } \\
\text { make the presentation } \\
\text { more interesting and } \\
\text { memorable } \\
\text { - Ensure the trainer is } \\
\text { comfortable and familiar } \\
\text { with the material and } \\
\text { has good presentation } \\
\text { skills, with the ability to } \\
\text { hold the audience's } \\
\text { interest } \\
\text { - Incorporate real-world } \\
\text { support as an aspect of } \\
\text { training; leverage } \\
\text { existing site networks to } \\
\text { provide training and } \\
\text { mentorship support } \\
\text { Focus on the application } \\
\text { of GCP principles learned } \\
\text { in training to real-world } \\
\text { situations encountered } \\
\text { in day-to-day workload }\end{array}$ & $\begin{array}{l}\text { pressure testing their understanding of it, } \\
\text { and they are really engaged in their } \\
\text { understanding beyond what they may } \\
\text { have done in the past. } \\
\text {... as a sponsor it's our responsibility to } \\
\text { provide training, but when we provided } \\
\text { these additional trainings, it's been really } \\
\text { helpful to bring in our steering committee } \\
\text { members to provide, like, case studies, } \\
\text { because a lot of our steering committee } \\
\text { members are leaders in the field. So, } \\
\text { there is more incentive for the PIs to } \\
\text { attend these trainings. Or research } \\
\text { coordinators will think it's more valued to } \\
\text { have a leader in the field speaking with } \\
\text { them and providing information that's } \\
\text { more valuable to them and to take time } \\
\text { out of their day. ... But, you know those } \\
\text { real world examples, having someone } \\
\text { presenting live in the teleconference that } \\
\text { is the key opinion leader in the field as } \\
\text { part of the presentation, and taking } \\
\text { questions from the research coordinators } \\
\text { and the Pls, I think you get better } \\
\text { attendance, I think you get better } \\
\text { interaction, and the information is } \\
\text { retained. } \\
\text { I think where the rubber meets the road } \\
\text { is how well does the trainer understand } \\
\text { them, and how comfortable are they with } \\
\text { the material and presentation skills. And }\end{array}$ \\
\hline
\end{tabular}




\begin{tabular}{|c|c|c|c|c|}
\hline \multirow[t]{2}{*}{ Topic } & \multicolumn{2}{|r|}{ Investigators } & \multicolumn{2}{|r|}{ Sponsors } \\
\hline & Change Suggested & Representative Quotes & Change Suggested & Representative Quotes \\
\hline & & & & $\begin{array}{l}\text { frankly, how engaging are they in getting } \\
\text { the attention of the people they are } \\
\text { training. Because GCP training tends to } \\
\text { be the most boring element of an SIV, for } \\
\text { example, and often that's where you lose } \\
\text { your audience. You know, all } \\
\text { investigators and coordinators believe } \\
\text { they know it well enough. But generally } \\
\text { speaking, they all have areas they aren't } \\
\text { strong at when it comes to GCP. So, } \\
\text { finding a way to present it that isn't it } \\
\text { just, "Let me read the reg to you and help } \\
\text { you understand how to interpret." That's } \\
\text { not engaging enough to get the attention } \\
\text { of a busy investigator, and as such, I } \\
\text { don't think it's very effective. }\end{array}$ \\
\hline $\begin{array}{l}\text { Training } \\
\text { Content }\end{array}$ & $\begin{array}{l}\text { - Prioritize important } \\
\text { topics, rather than } \\
\text { repeating everything } \\
\text { every time } \\
\text { - Critical to present } \\
\text { historical origins of } \\
\text { GCP (e.g., the Belmont } \\
\text { Report, Tuskegee } \\
\text { Experiment) to new } \\
\text { investigators, but not } \\
\text { necessary to repeat it } \\
\text { at subsequent GCP } \\
\text { trainings } \\
\text { - Emphasize new } \\
\text { material in repeat } \\
\text { training sessions, } \\
\text { particularly in the }\end{array}$ & $\begin{array}{l}\text { But part of the problem is not that we } \\
\text { repeat it, but we're trying to repeat } \\
\text { everything, and that just doesn't help, } \\
\text { and that's where I think people get } \\
\text { frustrated. And they find they are hearing } \\
\text { this big message, and they can't } \\
\text { remember any of it, and they have to } \\
\text { hear it again. And we're not doing a good } \\
\text { job of communicating and prioritizing } \\
\text { and being a little more strategic about } \\
\text { how we communicate this information. } \\
\text { I think what re-certification ought to be } \\
\text { emphasizing, is new material. ... the } \\
\text { design of clinical research trials is } \\
\text { changing, and you know, like the I-SPY } \\
\text { trials and that sort of thing with different }\end{array}$ & $\begin{array}{l}\text { Focus on consequences } \\
\text { that occur if GCP is not } \\
\text { followed, both as a } \\
\text { cautionary tale and as a } \\
\text { means of motivating } \\
\text { trainee interest } \\
\text { - Tailor training to } \\
\text { trainees' knowledge and } \\
\text { experience }\end{array}$ & $\begin{array}{l}\text { I conduct lots of trials, and I hear the } \\
\text { same thing every time, so I think it's } \\
\text { incumbent on sponsors to freshen it up. } \\
\text { Make it interesting, give recent examples } \\
\text { of things, not just things that have gone } \\
\text { wrong, although that certainly tends to } \\
\text { get their attention, but also what's going } \\
\text { right, has worked extremely well. If it's a } \\
\text { repeat site for you, and you know them, } \\
\text { and you know what they do well, then } \\
\text { highlight that. } \\
\text { But ultimately, it's about why each of the } \\
\text { GCP principles are important, and I } \\
\text { wonder if you can almost do a skit or a } \\
\text { video of patients who go through trials } \\
\text { where these items aren't followed. }\end{array}$ \\
\hline
\end{tabular}




\begin{tabular}{|c|c|c|c|c|}
\hline \multirow[t]{2}{*}{ Topic } & \multicolumn{2}{|r|}{ Investigators } & \multicolumn{2}{|r|}{ Sponsors } \\
\hline & Change Suggested & Representative Quotes & Change Suggested & Representative Quotes \\
\hline & $\begin{array}{l}\text { context of new } \\
\text { technology and the } \\
\text { changing trials } \\
\text { landscape } \\
\text { - Provide more real- } \\
\text { world context and } \\
\text { situational examples }\end{array}$ & $\begin{array}{l}\text { formats, that's the kind of useful } \\
\text { information that would be really good to } \\
\text { the focus of retraining. New stuff. Not old } \\
\text { stuff re-hashed over and over again. } \\
\text { I think some of the questions that they } \\
\text { ask in the GCP exam are situational } \\
\text { questions, and I think those are good, } \\
\text { because they really force you to kind of } \\
\text { think about how to apply the guidance. I } \\
\text { also think that a lot of times the criteria } \\
\text { aren't always black and white. They seem } \\
\text { black and white when you're reading } \\
\text { them, but there's a lot of gray area that } \\
\text { comes up in the actual practice. If you } \\
\text { look at communications that happen in } \\
\text { different forms, like site forms, lots of } \\
\text { people have the same questions and } \\
\text { issues that come up over and over again. } \\
\text { There are different ways to interpret the } \\
\text { guidance. So, I think instead of having } 13 \\
\text { points that are each one sentence long, } \\
\text { maybe [add] some more context to it, } \\
\text { and some examples or something with } \\
\text { situations. }\end{array}$ & & $\begin{array}{l}\text { Because you would watch that video and } \\
\text { say, "Oh my gosh, I would never do that." } \\
\text { Or, "that's horrible, how could they do } \\
\text { that." But then when you kind of go } \\
\text { through the mistakes, they think they are } \\
\text { minor mistakes, like, "I did get their } \\
\text { consent, but they didn't date it." Or, } \\
\text { "They couldn't sign, so somebody else } \\
\text { signed it." Whatever it might be. I think } \\
\text { that at the point in time where people } \\
\text { make mistakes with GCP, they don't } \\
\text { really always understand the } \\
\text { repercussions of that.... I think maybe } \\
\text { even vignettes are helpful. We started } \\
\text { adding to our GCP training the most } \\
\text { common forty-three findings that some } \\
\text { inspectors are documenting each year. } \\
\text {...Because at the end of the day, there are } \\
\text { reasons we have to follow GCP, but again } \\
\text { people get lazy, or they get busy and they } \\
\text { become sloppy. And so just to kind of } \\
\text { reiterate, there are reasons why we have } \\
\text { to follow these, and there are } \\
\text { consequences for not following them. } \\
\text { I think the hardest part is, or the most } \\
\text { important part of training is to } \\
\text { understand the person you're training } \\
\text { where their gaps are in experience and } \\
\text { where you need to focus your time. }\end{array}$ \\
\hline
\end{tabular}

Table 5. Feedback on Improvements to GCP Training in General and Suggested Solutions by Respondent Type 


\section{DISCUSSION}

Our findings highlight that clinical investigators and sponsors recognize that one or more GCP principles can be linked to the critical tasks necessary for the quality conduct of clinical trials; however, they articulated the need for significant improvement in the design, content, presentation, and training of GCP guidelines. Respondents found the current content of GCP training materials to be redundant, unengaging, and uninteresting. While respondents acknowledged the importance of GCP principles, they disclosed that, due to the burden of trainings and time constraints, GCP training has become another item to mark off the study initiation checklist rather than a learning opportunity and way to meaningfully engage with GCP content. Ideally, as described by some respondents, GCP training should focus on the key takeaways of GCP principles and not require time spent on non-critical elements such as the history and development of GCP.

Respondents also suggested that GCP training should be formatted in a manner that actively engages trainees by providing real-world examples that focus on applications in daily clinical research practice. For example, the GCP principle of informed consent could be better operationalized by trainees if the training provided hands-on application of how to write consent forms that both satisfy ethical and scientific requirements as well as improve consent form comprehension for research participants. This follows the competency-based education approach to clinical trial education by the Clinical and Translational Science Awards (CTSA) Consortium, which calls for training on necessary skills to perform specific job tasks, such as proper handling of investigational products and financial management of clinical sites [17]. The Network of Networks (N2) program, a non-profit collaboration among clinical research organizations in Canada, pairs mentors with at least 5 years of clinical research experience and therapeutic area expertise with less experienced mentees to facilitate knowledge and skill building by filling in the gaps of formal research training [18]. In addition, the Rockefeller University Navigation 
Program, where experienced research coordinators mentor less experienced investigators, has shown success in expediting IRB approval of protocol submissions [19].

The findings from our study are in line with recommendations released by the CTSA Consortium Enhancing Clinical Research Professionals' Training and Qualification (ECRPTQ) project calling for GCP trainings that are reciprocally accepted by sponsors in an effort to reduce redundant training requests [2]. The CTSA Consortium accepted the industry standard of having GCP refresher trainings every 3 years, but further research should be conducted to better ascertain the right training frequency to simultaneously reduce redundancy and protect patient safety [2].

Our study is not without limitations. This study represents only the viewpoints of those interviewed about the quality conduct of clinical trials and ways to modify GCP training, and thus may not represent the perspectives of other investigators and sponsors. However, we anticipate that these findings may be broadly applicable to many stakeholders who are expected to follow GCP guidelines in the course of engaging with the clinical trial enterprise.

Following the CTTI methodology [20], the findings contributed to the development of recommendations for stakeholders to improve GCP training to ensure the quality conduct of sponsored clinical trials [21]. By revising the methods and content of GCP training, we can move beyond qualification as a check-box activity and instead use GCP as a critical training tool to enhance the quality conduct of clinical trials. Of note, the current version of GCP-ICH E6 R2-is under revision, although training frequency and other requirements are currently not prescribed by $\mathrm{ICH}$ but are instead being determined by research sponsors and institutions. 


\section{Funding}

Funding for this work was made possible, in part, by the Food and Drug Administration through cooperative agreement U18FD005292 and grant R18FD005292. Views expressed in written materials or publications and by speakers and moderators do not necessarily reflect the official policies of the Department of Health and Human Services, nor does any mention of trade names, commercial practices, or organization imply endorsement by the United States Government. Partial funding was also provided by pooled membership fees from the Clinical Trials Transformation Initiative's (CTTI) member organizations.

\section{Acknowledgments}

The authors wish to thank participants for sharing their perspectives with us. The authors also acknowledge the contributions of the CTTI Investigator Qualification team, former project managers Jennifer Goldsack and Kirsten Wareham, and to Liz Wing for editorial assistance. 


\section{REFERENCES}

1. Arango J, Chuck T, Ellenberg SS, et al. Good Clinical Practice Training: Identifying Key Elements and Strategies for Increasing Training Efficiency. Ther Innov Regul Sci. 2016;50:480-486. doi: $10.1177 / 2168479016635220$.

2. Shanley TP, Calvin-Naylor NA, Divecha R, et al. Enhancing Clinical Research Professionals' Training and Qualifications (ECRPTQ): Recommendations for Good Clinical Practice (GCP) training for investigators and study coordinators. J Clin Transl Sci. 2017;1:8-15. doi: 10.1017/cts.2016.1.

3. Kaur G, Smyth RL, Powell CV, Williamson P. A survey of facilitators and barriers to recruitment to the MAGNETIC trial. Trials. 2016;17:607. doi: 10.1186/s13063-016-1724-3.

4. Mentz RJ, Hernandez AF, Berdan LG, et al. Good Clinical Practice Guidance and Pragmatic Clinical Trials: Balancing the Best of Both Worlds. Circulation. 2016;133:872-80. doi:

10.1161/CIRCULATIONAHA.115.019902.

5. Society for Clinical Research Sites. The Quest for Site Quality and Sustainability: Perceptions, Principles and Best Practices. 2014.

6. Macefield RC, Beswick AD, Blazeby JM, Lane JA. A systematic review of on-site monitoring methods for health-care randomised controlled trials. Clin Trials. 2013;10:104-24. doi: $10.1177 / 1740774512467405$.

7. Johnston SC, Lewis-Hall F, Bajpai A, et al. It's Time to Harmonize Clinical Trial Site Standards [Discussion Paper]. Vol. 2019. National Academy of Medicine Perspectives; 2017.

8. Clinical Trials Transformation Initiative. Good Clinical Practice Training for the Conduct of Clinical Trials: Literature Review Report. 2015.

9. Clinical Trials Transformation Initiative. CTTI Recommendations: Good Clinical Practice (GCP) Training for Investigators. 2015. 
10. Sandelowski M. Whatever happened to qualitative description? Res Nurs Health. 2000;23:33440.

11. Sandelowski M. What's in a name? Qualitative description revisited. Res Nurs Health. 2010;33:77-84. doi: 10.1002/nur.20362.

12. Patton MQ. Qualitative Research \& Evaluation Methods. 3rd ed Thousand Oaks, California: SAGE Publications; 2001.

13. International Council for Harmonisation of Technical Requirements for Pharmaceuticals for Human Use (ICH). Integrated Addendum to ICH E6(R1): Guideline for Good Clinical Practice E6(R2). 2016:59.

14. U.S. Food and Drug Administration. Good Clinical Practice 101: An Introduction. Vol. 2019:Slides 12-14.

15. McLellan E, MacQueen KM, Neidig JL. Beyond the Qualitative Interview: Data Preparation and Transcription. Field Methods. 2003;15:63-84.

16. Guest G, MacQueen K, Namey E. Applied Thematic Analysis. Thousand Oaks, California: SAGE Publications; 2012.

17. Calvin-Naylor NA, Jones CT, Wartak MM, et al. Education and training of clinical and translational study investigators and research coordinators: a competency-based approach. J Clin Transl Sci. 2017;1:16-25. doi: 10.1017/cts.2016.2.

18. Furimsky I, Arts K, Lampson S. Developing a successful peer-to-peer mentoring program. Applied Clinical Trials. 2014;22:27-30.

19. Brassil D, Kost RG, Dowd KA, Hurley AM, Rainer TL, Coller BS. The Rockefeller University Navigation Program: a structured multidisciplinary protocol development and educational program to advance translational research. Clin Transl Sci. 2014;7:12-9. doi: 10.1111/cts.12134. 
20. Corneli A, Hallinan Z, Hamre G, et al. The Clinical Trials Transformation Initiative: Methodology supporting the mission. Clin Trials. 2018;15:13-18. doi: 10.1177/1740774518755054.

21. Clinical Trials Transformation Initiative. CTTI Recommendations: Identifying Qualified Investigators and Their Delegates to Conduct Sponsored Clinical Trials. 2018. 